\title{
Congo Red Azo Dye Removal and Study of Its Kinetics by Aloe Vera Mediated Copper Oxide Nanoparticles
}

\author{
Madiha Batool ${ }^{1, *}$, Muhammad Zahid Qureshi ${ }^{1}$, Farwa Hashmi ${ }^{2}$, Nida Mehboob ${ }^{2}$, and Abdul Salam \\ Shah $^{3}$ \\ ${ }^{1}$ Department of Chemistry, Government College University, Katchery Road, Lahore 54000, Pakistan \\ ${ }^{2}$ Post Graduate Islamic College, (PGICC), Lahore, Pakistan \\ ${ }^{3}$ Institute of Post Graduate Studies (IPS), University of Kuala Lumpur (UniKL-MIIT), Kuala Lumpur, Malaysia
}

\section{* Corresponding author:}

tel: $+92-313-4612126$

email: tweetchem56@gmail.com

Received: May 20, 2018

Accepted: December 20, 2018

DOI: $10.22146 /$ ijc. 35626

\begin{abstract}
Nanotechnology is generating interest of researchers toward cost-free and environment-friendly biosynthesis of nanoparticles. In this research, biosynthesis of stable copper nanoparticles has been done by using aloe vera leaves extract which has been prepared in de-ionized water. The aim of this study is the tracing of an object by green synthesis of copper oxide nanoparticles with the interaction of leaves extract and copper salt and its dye removal efficiency. The results have confirmed the efficient removal of Congo red (CR) dye using copper oxide nanoparticles. Furthermore, we have examined the effect of variables like concentration, time, $p H$, and adsorbent dosage. We have observed maximum $1.1 \mathrm{mg} / \mathrm{g}$ dye removal at $10 \mathrm{~min}$ time interval, $\mathrm{pH} 2$, and $5 \mathrm{mg} / \mathrm{g}$ nanoparticles. The shape of the copper nanoparticles was spherical, and their range of grain was 80-120 nm. The EDX of synthesized nanoparticles showed copper 38\% and 65\% oxygen. UV spectrophotometer analysis confirms peak of the copper nanoparticles between 200-600 $\mathrm{nm}$.
\end{abstract}

Keywords: aloe vera; SEM; copper oxide nanoparticles; green synthesis; XRD

\section{- INTRODUCTION}

Recent advancements in the field of science and technology, particularly nanotechnology, have emerged the need for development in the synthesizing of nanosized particles of desired size and shape [1]. Textile industries are the most common sectors in the world which uses dye to color the fabrics. The part of the economy of a country like Pakistan depend on the textile sector, but the wastage of water is not good for future generations. The Pakistan Council of Research in Water Resources has already warned that Pakistan will face scare shortage of water by the year 2030 if the wastage of water has not avoided. The toxic materials released and used during the dye process may cause serious health issues which might be tackled otherwise the ration of diseases caused by dye detergents will increase to severe level.

The high volume of water consumption and wastewater characteristics, such as dyes and detergents used in the process are the parameters that have caused a serious effort to find reasonable technologies to cure textile industry wastewater. In this regard, research has been carried out on the biosynthesis to avoid the water waste and release of toxic chemicals. The researchers and scientists are working in this area for the last decades [2].

There is a scope to produce new methods for the production of nanoparticles which should be required inexpensive reagent, less severe reaction condition and eco-friendly. Further exploration of new natural plants is the need so that we can use them as reducing agents. In recent years, copper oxide $(\mathrm{CuO})$ nanoparticles have attracted much attention from researchers due to its application in wound dressings and biomedical properties [3]. Nanotechnology deals with the manipulation of the low size usually less than $100 \mathrm{~nm}$ [45]. Literature has revealed that the chemical and physical methods can prepare the metallic nanoparticles. Both 
the chemical and physical processes have certain flaws like toxic chemicals, and they are also dangerous to the environment [6-7]. The poisonous chemicals cause environmental pollution, which puts many lives at risk of being highly exposed to respiratory and skin diseases. The air pollution is also the biggest concern of nowadays due to the increased number of factories and other machinery. The research has now diverted to green chemistry which plays the prominent part in nanotechnology to benefit the society. It has observed that the surface area and mass ratios increase adsorption property. Therefore, the need for the development of a clean, reliable, biocompatible, benign and eco-friendly process to synthesize nanoparticles forced many researchers to develop green chemistry and bioprocesses [8].

For the highly stabilized nanoparticles, green synthesis has been successfully used [9]. The maintenance of the integrity of nanoparticles is one of the challenges of green synthesis. Different researchers have used plants for the synthesis like copper nanoparticles has been synthesized by leaf extract of aloe vera plant in [10]. The green synthesis of the copper nanoparticle is a speedy, economically feasible, and efficient method. Phenolic content in plant extracts dissolved in water, degradable and catalyzed the synthesis of the nanoparticle as capping reducing agent [11]. Synthesis of metal nanoparticles shows unusual structural, electrical, optical and magnetic properties [12]. The unique properties of nanoparticles can tailor to the growth of nanoparticles, so the development of green methods of synthesis is mandatory which have lesser detrimental effects on the environment [13].

The aloe vera plant has several benefits due to its rich medication and cosmetic properties. Several clinical trials are being conducted to further evaluate the use of aloe vera gel for a variety of disorders [3]. Aloe vera juice has commonly used as a cream for burns and skin abrasions [14]. It has observed that the functional groups in aloe vera contain, carboxymethyl-O- $\mathrm{CH}_{2}-\mathrm{COO}^{-}$and sulphoxy $-\mathrm{O}-\mathrm{CH}_{2}-\mathrm{CHOH}-\mathrm{CH}_{2}-\mathrm{O}-\mathrm{CH}_{2}-\mathrm{CH}_{2} \mathrm{SO}_{3}{ }^{-} \quad[15,16]$. We cannot ignore its healing abilities also it has been commonly used in the cosmetics and skin creams due to its cleaning and anti-aging effects [17-18].
Furthermore, aloe vera contains antioxidant vitamins like $\mathrm{A}, \mathrm{C}$, and vitamin $\mathrm{B} 12$, folic acid, and choline. It contains eight enzymes, namely aliases, alkaline phosphatase, amylase, bradykinase, carboxypeptidase, catalase, and cellulase [19-20]. The Aloe vera plant is also rich in minerals such as calcium, copper, selenium, chromium, manganese, magnesium, potassium and zinc. The leaves of aloe vera provide anthraquinones, like aloin and emodin, which act as analgesics, antibacterial. It contains fatty acids including cholesterol, campesterol, and beta-sitosterol [21]. The plant contains a total of 75 potentially active constraints [22].

Due to rich properties, we have selected aloe vera plant for the synthesis and removal of Congo red dye. In this study, we intend to remove Congo red dye from its aqueous solution by nanoparticles. The detailed analysis of the copper oxide nanoparticles has also carried out. The detailed experimental setup and process have explained in subsequent sections.

\section{- EXPERIMENTAL SECTION}

The experimentation has been carried out in the chemistry laboratory in a controlled environment and keeping in consideration the given experimental standards. We have created the detailed experimental setup for the better understanding, which explain each step of the experiment in detail. We have divided experimentation into two parts; the first one is the synthesis of $\mathrm{CuO}$ nanoparticles and analysis of for the confirmation of the formation of nanoparticles. The second part is the Congo red dye removal. The subsections describe detailed procedure adopted for the synthesis and Congo red dye removal.

\section{Materials}

The selection and the proper arrangement of materials plays an essential role in the success of experimentation in the chemical laboratory. All the chemicals used in this study have analytical GR grade and $99.8 \%$ purity. The following materials have used for the experimentation, i.e., aloe vera leaves, copper sulfate $\left(\mathrm{CuSO}_{4}\right)$, Congo red dye and distilled water. 


\section{Instrumentation}

The instruments used for the experimentation were SEM (JSM-6480), XRD (XPERT-PRO), UV spectrophotometer (DB-20), Whatman filter paper with pore size of $0.2 \mu \mathrm{m}$, knife, mortar and pestle, spill trough, burner, tripod, centrifuge, muffle furnace, test tubes, conical flask, beaker, tongs, bunsen burners, droppers and funnel.

\section{Procedure}

\section{Collection and preparation of plant leaf extract}

The preparation of plant leaves extract was the essential component of an experiment. Total $150 \mathrm{~g}$ of aloe vera has collected from the nearby garden. The leaves of aloe vera were separated from the gel part of aloe vera. The soil and dust particles have been removed from the separated aloe vera leaves using distilled water. The leaves have been thoroughly dried and chopped for further experimentation.

\section{Green synthesis of CuO nanoparticles}

The process of synthesis starts with the selection of a natural reducing agent after selection chopping prepares the extract of the natural reducing agent and boiling the natural reducing agent in distilled water at a specific temperature. The prepared leaves extract needs to mix up with copper sulfate solution. Then the resultant mixture needs to be stirred using a magnetic stirrer at a certain speed and for the selected period. The next stage is the centrifuge in which the resultant solution need to centrifuge at a certain speed for separation of $\mathrm{CuO}$ nanoparticles. After centrifugation, the resultant nanoparticles need to be heated up at a higher temperature. The final stage is the cooling down of the solution and keeping it safe for the experimentation.

Keeping in view the benefits and properties of aloe vera plant as stated earlier, we have selected the said plant for the experimentation and removal of Congo red dye using $\mathrm{CuO}$ nanoparticles. We have collected aloe vera leaves from the nearest garden of the Institute and used as a natural reducing agent. First, $120 \mathrm{~g}$ of the leaves of the aloe vera plant has been separated and observed thoroughly and washed with distilled water. The washing of leaves has been carried out to remove the dust particles which can interrupt the purity of the solution. For better results and experimentation the purity of the extract is essential. After washing the next step is drying of the leaves which were carried out in a container to avoid mixture of dust particles. The dried leaves have been ground using a mortar and pestle. The resultant ground leaves were saved in a spill trough. The boiling of the ground leaves was the next step which was carried out using Florence flask of $250 \mathrm{~mL}$ and burner. The boiling of the ground leaves has been carried out using deionized water at $100{ }^{\circ} \mathrm{C}$ (approximately) for $10 \mathrm{~min}$. After that, the filtration has been carried out. For the filtration, the solution was passed through a filter paper for the removal of any solid particles, and the resultant solution was filtered again through a Whatman filter paper with a pore size of $0.2 \mu \mathrm{m}$.

Finally, the filtrate has been stored at $6^{\circ} \mathrm{C}$ as a stock for the synthesis of $\mathrm{CuO}$ nanoparticles and named as aloe vera leaves extract. At this stage, we are all set to perform the experimentations. Next step is the preparation of a mixture of aloe vera leaves extract and copper sulfate solution. The copper sulfate $\left(\mathrm{CuSO}_{4} \cdot 5 \mathrm{H}_{2} \mathrm{O}\right)$ was used as an antecedent. The pentahydrate $\left(\mathrm{CuSO}_{4} \cdot 5 \mathrm{H}_{2} \mathrm{O}\right)$ has a bright blue color. When we dissolve the copper sulfate in water, it forms an aquo complex $\left[\mathrm{Cu}\left(\mathrm{H}_{2} \mathrm{O}\right)_{6}\right]^{2+}$, having octahedral molecular geometry.

For the preparation of a mixture of aloe vera leaves extract, $15 \mathrm{~mL}$ aloe vera leaves extract has been used and mixed up with $50 \mathrm{~mL}$ of copper sulfate solution. The resultant solution was stirred on a magnetic stirrer at a temperature of $120^{\circ} \mathrm{C}$. The color change was observed at saturation point from deep blue to pale and then dark red. Brick red color confirms the nanoparticles formation. Due to copper cations, reduced $\mathrm{CuO}$ atoms converted to copper atom clusters. The resultant solution was centrifuged for $10 \mathrm{~min}$ at a speed of $50000 \mathrm{rpm}$. After discarding supernatant, copper oxide nanoparticles has been dried in a watch glass for further experimentation and detailed study. After cooling of the copper oxide nanoparticles, thoroughly washing with distilled water and then calcined at $52-60^{\circ} \mathrm{C}$ has been carried out. The resultant nanoparticles were heated at $500^{\circ} \mathrm{C}$ for $3 \mathrm{~h}$ using 


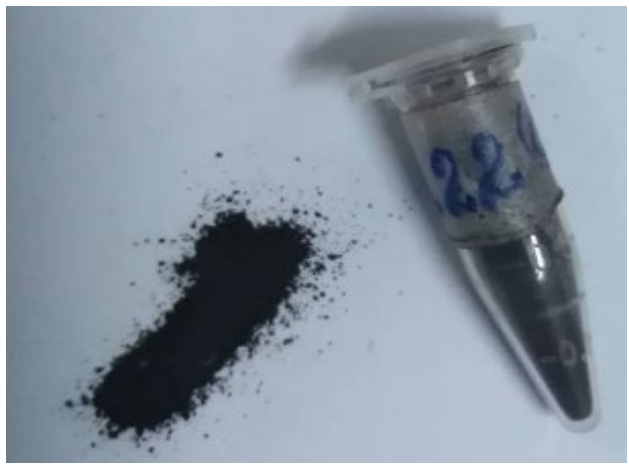

Fig 1. Solid $\mathrm{CuO}$ nanoparticles

a muffle furnace. The color of the product thus obtained is black indicating the formation of copper oxide nanoparticles. After drying, black color assembled for further characterization. Finally, after the complete process discussed above, we are all set to perform the detailed study on the nanoparticles, and proceed with the removal of Congo red dye. The output of the whole process is the solid $\mathrm{CuO}$ nanoparticles same can be seen in Fig. 1.

\section{Removal of Congo red dye}

The removal of Congo red dye will be carried out using the $\mathrm{CuO}$ nanoparticles created during synthesis.

\section{Preparation of $\mathbf{1 0 0 0} \mathbf{~ m g / L}$ Congo red dye solution. A} $1000 \mathrm{mg} / \mathrm{L}$ solution of Congo red (CR) has been prepared by dissolving dye in $1 \mathrm{~L}$ distilled water. Initially, $100 \mathrm{mg} / \mathrm{L}$ solution from $1000 \mathrm{mg} / \mathrm{L}$ solution has been prepared after dilution. After that, the solutions of 150, 200, $250 \mathrm{mg} / \mathrm{L}$ were prepared. The color removal efficiency was calculated using Eq. (1) [23]. Where A is a concentration of dyes before adding nanoparticles and $\mathrm{B}$, represent its concentration after adding nanoparticles as an adsorbent. Percentage decolorization of Congo red $(\%)=\frac{A-B}{B}{ }^{*} 100 \%$

The procedure of Congo red dye removal. The experiment was carried out by introducing $25 \mathrm{ppm}$ in a solution of the Congo red dye and exposing it to UV light for $3 \mathrm{~h}$ in a Haber Multi-Lamp Photoreactor. The UV absorption profile of the dye was studied for every $30 \mathrm{~min}$ after the addition of the synthesized $\mathrm{CuO}$ nanoparticles. Initially, quantity taken was $20 \mathrm{~mL}$ of dye solution and, 4 $\mathrm{mg}$ of aloe vera green synthesized copper nanoparticles.

\section{Detailed study of CuO nanoparticles}

The next step of the experiment is the characterization of green synthesized nanoparticles. The morphological, structural and chemical composition of $\mathrm{CuO}$ nanoparticles has been analyzed using Scanning Electron Microscope (SEM) (JSM-6480) and X-ray diffractometers (XRD) (XPERT-PRO) equipment. The optical properties of synthesized particles have been investigated using UV spectrophotometer (DB-20). The size and shape of copper oxide nanoparticles have been observed using SEM (JSM-6480). The examination of the crystal structure of synthesized nanoparticle has been carried out using XRD (XPERT-PRO). FourierTransform infrared spectroscopy (FTIR) analysis were performed for the collection of the functional groups, present in this synthesis of $\mathrm{CuO}$ nanoparticles.

The further studies include; color change observation, time effect on Congo red dye removal, $\mathrm{pH}$ effect on dye removal, the effect of nanoparticles concentration on dye removal, and different kinetic studies.

\section{- RESULTS AND DISCUSSION}

\section{Color Change Observation}

For the confirmation of the formation of copper oxide nanoparticles, the color change was observed. The blue color solution has turned into black indicated the formation of copper nanoparticles synthesis.

\section{X-Rays Diffraction Studies}

The X-ray diffraction pattern of copper oxide nanoparticles was examined by $\mathrm{X}$-ray diffractometer (XPERT-PRO) [25]. The powder was added in the XRD cubes for analysis to determine the intensity of copper oxide nanoparticles. The resultant pattern of the copper oxide nanoparticles was matched with JCPDS card number (033-0480), the peaks at $2 \theta$ intensity 28.09, $30.61,36.14$ and 44.14 and have 112,103, 202 and 213 patterns, respectively.

However, the average crystal size calculated by the Scherrer equation keeping $\lambda$ at 0.154 and FWHM value calculated 0.5 found was $17.2 \mathrm{~nm}$. The shapes of the 


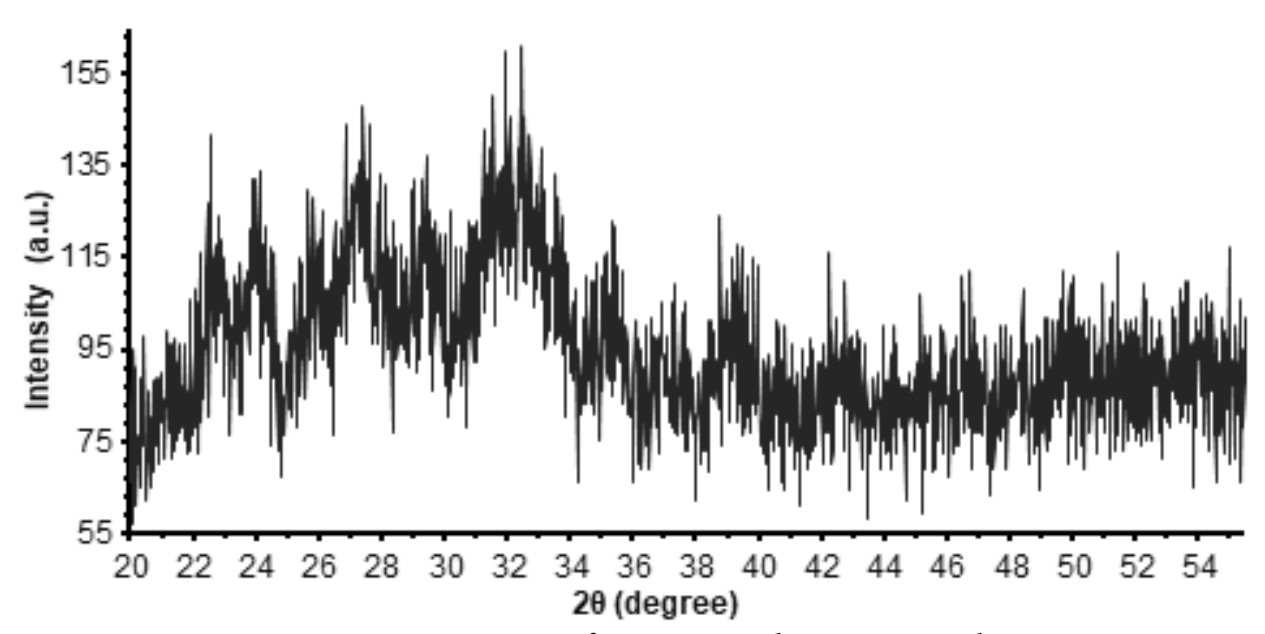

Fig 2. XRD pattern of copper oxide nanoparticles

Table 1. XRD pattern of copper oxide nanoparticles

\begin{tabular}{lllc}
\hline Name and Formula & & Crystallographic parameters & \\
\hline Reference code & $00-033-0480$ & Crystal system & Tetragonal \\
Mineral name & Paramelaconite & Space group & I41/amd \\
Compound name & Copper Oxide & Space group number & 141 \\
PDF index name & $\mathrm{Copper} \mathrm{Oxide}$ & $\mathrm{a}(\AA)$ & 5.8370 \\
Empirical formula & $\mathrm{Cu}_{4} \mathrm{O}_{3}$ & $\mathrm{~b}(\AA)$ & 5.8370 \\
Chemical formula & $\mathrm{Cu}_{4} \mathrm{O}_{3}$ & $\mathrm{c}(\AA)$ & 9.99320 \\
& & Alpha $\left(^{\circ}\right)$ & 90.0000 \\
& & Beta $\left(^{\circ}\right)$ & 90.0000 \\
& & Gamma $\left(^{\circ}\right)$ & 90.0000 \\
& & Calculated density & 5.93 \\
& & Measured density & 6.04 \\
& & Volume of cell & 338.39 \\
& & RIR & 16.28 \\
\hline
\end{tabular}

particles of $\mathrm{Cu}_{4} \mathrm{O}_{3}$ nanoparticles in XRD was tetragonal. The mineral name was paramelaconite, having space group $141 / \mathrm{amd}$, density $5.93 \mathrm{~g} / \mathrm{cm}^{3}$. The values of a, b, c were 5.8, 5.8, $9.9 \AA$. The sized of particles has been calculated using the Scherrer equation expressed in Eq. (2) [24].

$$
\mathrm{r}=\frac{\mathrm{K} \lambda}{\beta \cos \theta}
$$

where $\mathrm{r}$ is the mean size of the particles, $\mathrm{K}$ denote the shape factor having value $0.9, \lambda$ is the wavelength of $\mathrm{X}$-ray mostly copper metal used in an instrument having value $1.5, \beta$ is the line broadening at half the maximum intensity, and $\theta$ is the Bragg angle [24]. The average size of the particle calculated was $15-20 \mathrm{~nm}$. Fig. 2 contains the XRD pattern of copper oxide nanoparticles. The detail of the same can be seen in Table 1 and 2 .

\section{Scanning Electron Microscope (SEM)}

The average particle size of copper nanoparticle has been analyzed using SEM model (JSM-6480) having an $80-120 \mathrm{~nm}$ range. Fig. 3 elaborates the SEM model (JSM-6480). After detailed experimentation, we have concluded that the copper oxide particles were smooth and spherical. The range of grain of copper oxide nanoparticles was calculated about 50.5-130 nm using SEM micrograph. We have performed experimentation with the magnification of 10000x. The images of copper oxide nanoparticles with different scaling ranges of 0.5 , 2, 10, 50, and $100 \mu \mathrm{m}$ are shown in Fig. 3 . 
Table 2. Peaks in XRD pattern of copper oxide nanoparticles

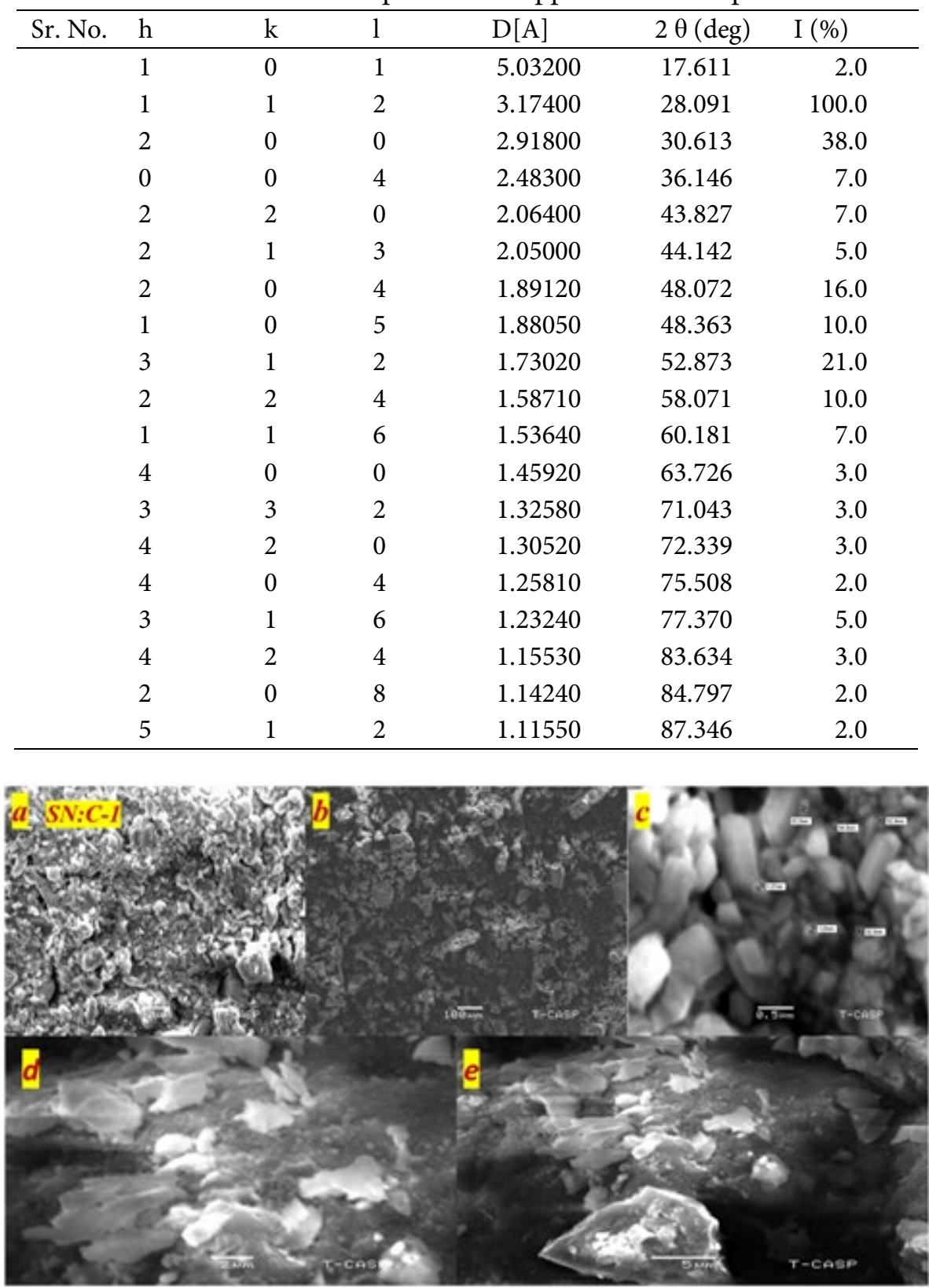

Fig 3. SEM images of copper oxide NPs

\section{EDX Analysis}

EDX image of copper oxide nanoparticles showed the composition of nanoparticles [25]. Image express the presence of $38 \%$ copper and $65 \%$ oxygen. The results of EDX analysis and data of nanoparticles is elaborated in Fig. 4, where the first peak is $\mathrm{O}$, the second peak is $\mathrm{Cu}$; the third peak is $\mathrm{Al}$, the fourth and fifth peaks represents $\mathrm{S}$ and finally $\mathrm{Cu}$ as in Table 3.

\section{FTIR Analysis}

In FTIR (IPRrestige-21) analysis spectrum has been analyzed. The detailed analysis has confirmed the presence of copper nanoparticles. Different peaks were observed at $1100 \mathrm{~cm}^{-1}$ and in the overall range of $650-$ $4000 \mathrm{~cm}^{-1}$ that confirmed the formation of copper oxide nanoparticles. The details are shown in Fig. 5. 


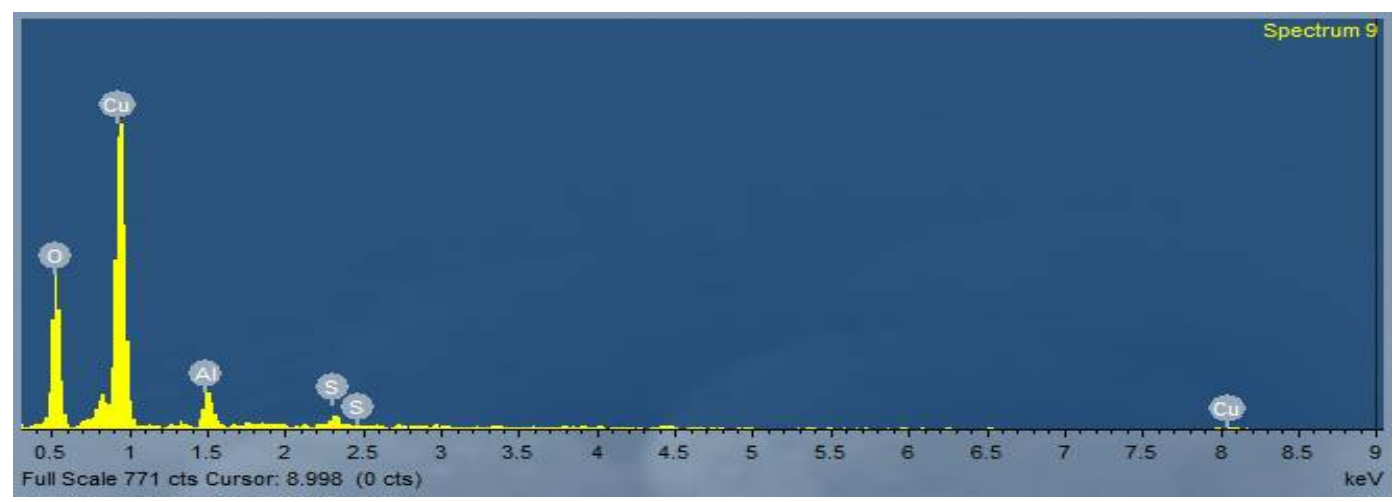

Fig 4. EDX of copper oxide nanoparticles

Table 3. EDX analysis

\begin{tabular}{lll}
\hline Sr. No & Position & Element \\
\hline 0.5 & $\mathrm{O}$ \\
0.9 & $\mathrm{Cu}$ \\
1.5 & $\mathrm{Al}$ \\
2.4 & $\mathrm{~S}$ \\
2.5 & $\mathrm{~S}$ \\
8 & $\mathrm{Cu}$ \\
\hline
\end{tabular}

The FTIR spectrum of copper oxide nanoparticles exhibits the broad absorption band at $3250 \mathrm{~cm}^{-1}$ that correspond to the hydroxyl $(\mathrm{OH})$ functional group in alcohols and phenolic compounds. The peak at 1601.2 $\mathrm{cm}^{-1}$ was due to $\mathrm{C}=\mathrm{C}$ aromatic bending. The absorption peak at $1038.0 \mathrm{~cm}^{-1}$ was due to stretching vibrations of $\mathrm{C}-\mathrm{O}$ group of primary and secondary Alcohols $(\mathrm{C}-\mathrm{O})$, while smaller peaks at $900-700 \mathrm{~cm}^{-1}$ was due to the aromatic bending vibration of $\mathrm{C}-\mathrm{H}$ group [26]. The FTIR analysis confirmed that obtained nanoparticle was not bare $\mathrm{CuO}$, but $\mathrm{CuO}$ coated with organic compounds from aloe vera. It has been concluded that the method reported in this paper cannot obtain pure $\mathrm{CuO}$. The peaks have been observed in FTIR, the same is reported in Table 4 . The FTIR spectra of the copper oxide nanoparticles is revealed in Fig. 5.

\section{UV Visible Spectra}

The presence of copper oxide nanoparticles was confirmed at the range of $100-1000 \mathrm{~nm}$. The eco-friendly method for the synthesis of copper oxide nanoparticles using aloe vera leaves extracts has been proved feasible,
Table 4. FTIR spectra analysis

\begin{tabular}{llll}
\hline No & Groups & Stretching or Bending & Peaks \\
\hline & O-H stretch & stretching & 3251 \\
& $\mathrm{C}-\mathrm{H}$ & stretching & 2860 \\
$\mathrm{C}=\mathrm{C}$ & aromatic bending & 1651 \\
& $\mathrm{C}=\mathrm{O}$ & stretching & 2250 \\
$\mathrm{CuO}$ stretch & stretching & 1100 \\
$\mathrm{C}-\mathrm{Cl}$ & stretching & $1150-1850$ \\
\hline
\end{tabular}

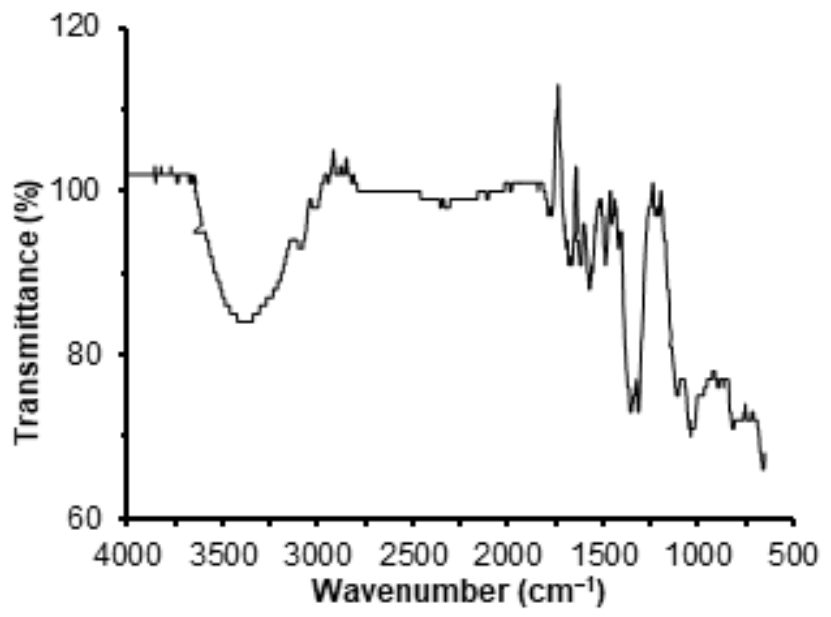

Fig 5. FTIR spectra of copper oxide nanoparticles

cost-free and reliable. UV-Vis spectra analysis has deceptively shown the formation of copper oxide nanoparticles. The synthesized nanoparticles can be utilized in the different fields. The maximum absorption peak between 200-300 $\mathrm{nm}$ has been observed. The highest peak at about $180-300 \mathrm{~nm}$ has been achieved which has confirmed the formation of the copper oxide nanoparticles as shown in Fig. 6. 


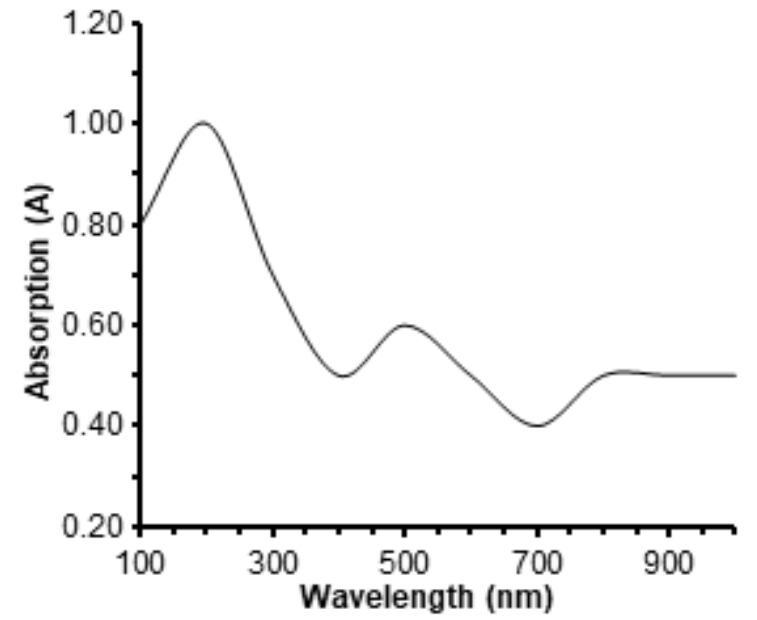

Fig 6. The conformation of copper oxide nanoparticles

\section{Time Effect on Congo Red Dye Removal}

The decolorization of Congo red dye at room temperature was analyzed. Initially, $20 \mathrm{~mL}$ dye solution has been taken, and $4 \mathrm{~mL}$ of green synthesized copper nanoparticles which was prepared using aloe vera leaves extract was dissolved in it. The prepared solution was heated for $10-20 \mathrm{~min}$ at $100{ }^{\circ} \mathrm{C}$. The change during the time interval was observed during the reaction. The removal of decolorization in $\mathrm{mg} / \mathrm{g}$ has been calculated and drawn graphically. The maximum time observed has been $120 \mathrm{~min}$ with highest $1.1 \mathrm{mg} / \mathrm{g}$ color removal at $10 \mathrm{~min}$ which has proved the rapid reaction of copper oxide $(\mathrm{CuO})$ nanoparticles. After this the decolorization was decreasing so we have kept the time up to $120 \mathrm{~min}$. The time effect on dye removal is graphically represented in Fig. 7.

\section{Effect of pH on Dye Removal}

The effect of $\mathrm{pH}$ was observed which has also affected the decolorization of dye. The aloe vera synthesized copper oxide nanoparticles showed maximum decolorization at a certain level when $\mathrm{pH}$ was increased and after that more increase has a negative effect on the decolorization. It happened due to the formation of more positive ions. The maximum decolorization was achieved as $1.1 \mathrm{mg} / \mathrm{g}$ with $\mathrm{pH}$ 2. The effect of $\mathrm{pH}$ on dye removal is graphically represented in Fig. 8 .

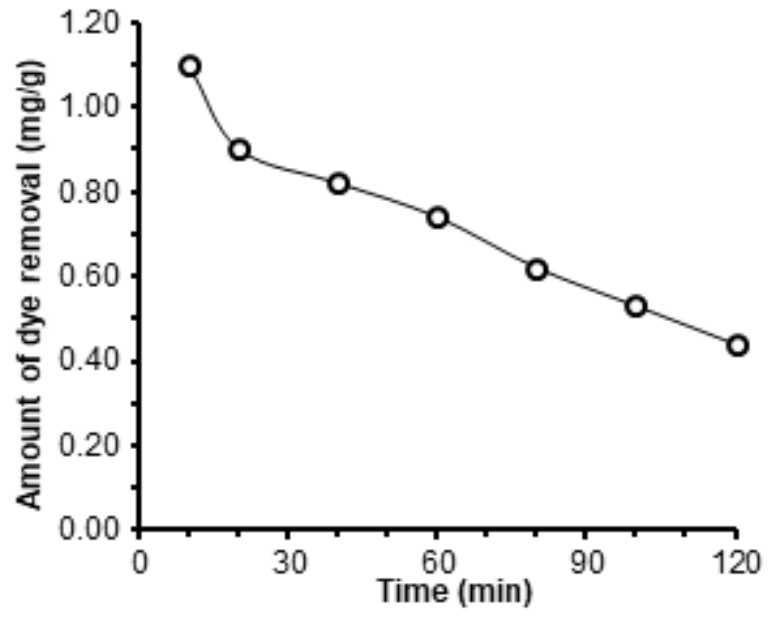

Fig 7. Effect of time on decolorization of Congo red

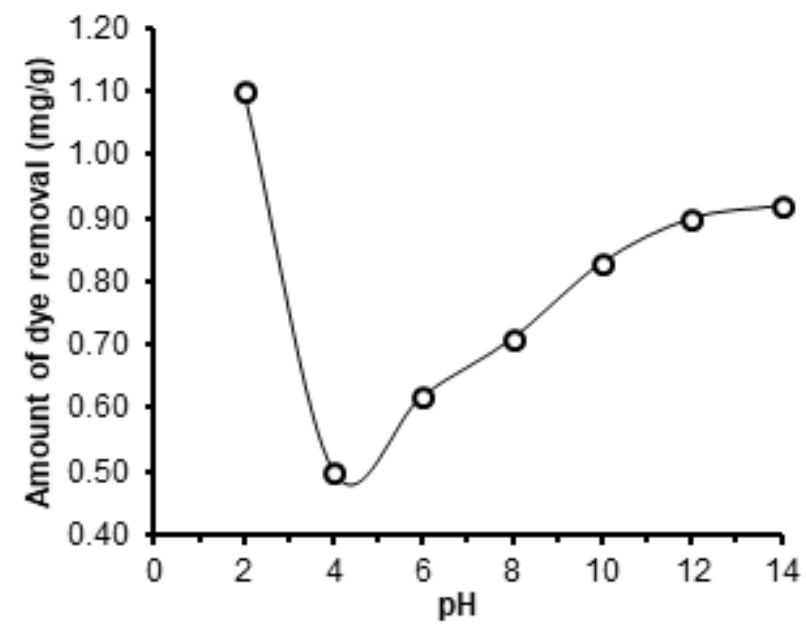

Fig 8. Effect of $\mathrm{pH}$ on the removal of Congo red dye

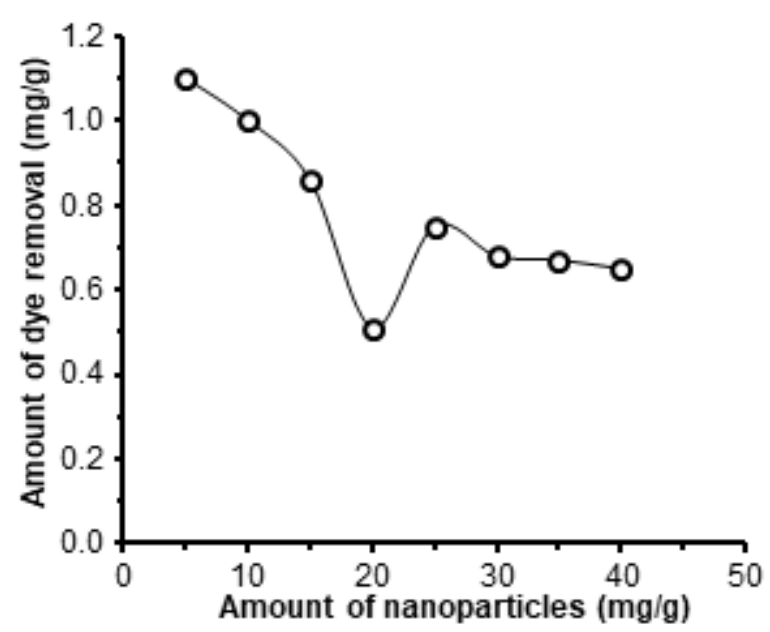

Fig 9. Effect of nanoparticles on dye removal 


\section{Effect of Nanoparticles Amount on Dye Removal}

The lower amount of $(5 \mathrm{mg} / \mathrm{g})$ nanoparticles played a considerable role in decolorization efficiency. The experimentation has been carried out using a different amount of nanoparticles from $1-40 \mathrm{mg} / \mathrm{g}$. The effect of the nanoparticles amount on Congo red dye was plotted in the form of a graph. The maximum amount of dye removal of $1.1 \mathrm{mg} / \mathrm{g}$ was observed at $5 \mathrm{mg} / \mathrm{g}$. After 40 $\mathrm{mg} / \mathrm{g}$ the dye removal has been gradually decreased. The concentration of the nanoparticles effect on decoloration of dye has been graphically represented in Fig. 9.

\section{Kinetic study of isotherm of CuO nanoparticles}

The kinetics of azo dye adsorption was carried out under selecting optimum operating conditions. The kinetic parameters are helpful for the estimation of the adsorption rate. A solution prepared by dissolving $2 \mathrm{~mL}$ of nanoparticle in $50 \mathrm{~mL}$ of $10 \mathrm{ppm}$ dyes and continuously stirred. The solution was heated if required. Ultraviolet spectrophotometer ultra mode was selected for data handling data after the collection was interpreted in graphical form. A relationship between different data parameter was checked for linearity. Rate constant was calculated from the graph. The constants obtained from adsorption kinetic models at $30^{\circ} \mathrm{C}$. Pseudo-second order kinetics curve linear fit of $\mathrm{t} / \mathrm{q}_{\mathrm{t}}$ can be determined using Eq. (3) the results can be seen in Fig. 10.

$$
\frac{\mathrm{t}}{\mathrm{q}_{\mathrm{t}}}=\frac{1}{\mathrm{k}_{2} \mathrm{q}_{\mathrm{e}}^{2}}+\frac{\mathrm{t}}{\mathrm{q}_{\mathrm{e}}}
$$

Pseudo-second order kinetic model fitted well with experimental data on dye degradation with $\mathrm{R}^{2}$ value of 0.989 , the rate constant $\left(\mathrm{k}_{2}\right)$ and the total adsorbed dye at equilibrium $\left(\mathrm{q}_{\mathrm{e}}\right)$ were $0.012 \mathrm{mg} / \mathrm{g} \mathrm{min}$ and $1.81 \mathrm{mg} / \mathrm{g}$, respectively.

\section{Comparison of the Isotherm Absorption Models}

\section{Langmuir isotherm curve}

Langmuir equation is a two-parameter equation study. This study reveals that adsorbents are adsorbed efficiently at a fixed rate, and only specified adsorbents are present at the reaction sites. Reaction sites on adsorbents is equally compelling. The interaction between adsorbate is absent [27]. The Langmuir Eq. (4) [28].

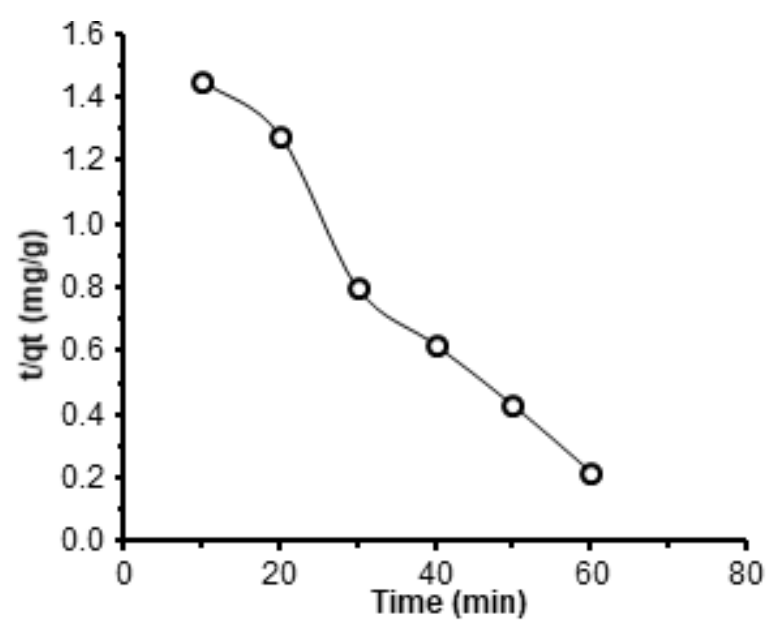

Fig. 10. Pseudo-second-order kinetics of copper oxide nanoparticles

$\mathrm{q}_{\mathrm{e}} / \mathrm{q}_{\mathrm{m}}=\frac{\mathrm{BC}_{\mathrm{e}}}{1+\mathrm{C}_{\mathrm{e}} / \mathrm{q}_{\mathrm{m}}}$

After plotting between $\left(\mathrm{C}_{\mathrm{e}} / \mathrm{q}_{\mathrm{e}}\right)$ and Ce slopes, the intercept was calculated. The separation factor RL was then determined using Eq. (5). Further, RL value greater than 1 indicates less adsorption, smaller than 1 shows favorable adsorption. The RL value of 1 indicates linear adsorption [29].

$\mathrm{R}_{\mathrm{L}}=1 /\left(1+\mathrm{BC}_{\mathrm{e}}\right)$

Present data shows the Langmuir isotherm model has good linearity which indicates there is strong attraction between Congo red dye and copper oxide nanoparticles with the $\mathrm{R}_{\mathrm{L}}$ value of 0.8 and $\mathrm{R}^{2}$ is 0.998 . This also confirms that Congo red dye could decolorized by $(\mathrm{CuO})$ nanoparticles efficiently as seen in Table 5 and Fig. 11.

\section{Freundlich isotherm model}

The Freundlich isotherm model is suitable for the adsorption of dye on the adsorbent. The Freundlich isotherm model fit least as compared to the Langmuir model. The Freundlich equation is stated below (Eq. (6)).

In $\mathrm{q}_{\mathrm{e}}=\mathrm{K}_{\mathrm{f}} \mathrm{q}_{\mathrm{m}}+1 / \mathrm{n} \ln \mathrm{C}_{\mathrm{e}}$

where $\mathrm{q}_{\mathrm{e}}$ is the concentration of azo dye used in $\mathrm{mg} / \mathrm{g}, \mathrm{C}_{\mathrm{e}}$ is the equilibrium concentration of the azo dye and $\mathrm{K}_{\mathrm{f}}$ and $\mathrm{n}$ are constants factors affecting the adsorption potential and adsorption speed. The graph between $\ln \mathrm{q}_{\mathrm{e}}$ versus $\ln C_{e}$ shows the least linearity for adsorption of azo 


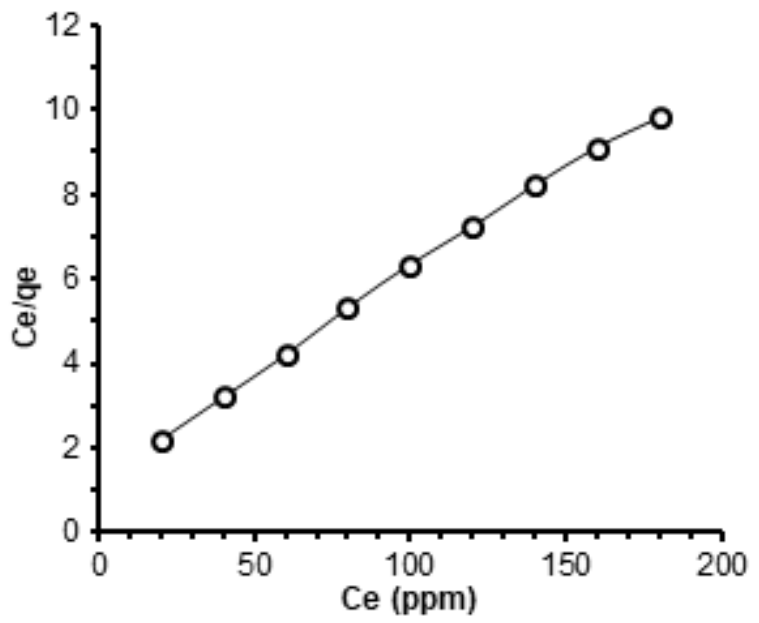

Fig 11. Langmuir isotherm graph

Table 5. Comparison of the isotherm adsorption models

\begin{tabular}{lcll}
\hline \multicolumn{2}{l}{ Langmuir isotherm } & \multicolumn{2}{l}{ Freundlich isotherm } \\
\hline $\mathrm{q}_{\mathrm{m}}(\mathrm{mg} / \mathrm{g})$ & 0.35 & $\mathrm{~K}_{\mathrm{f}}(\mathrm{mg} / \mathrm{g})$ & 0.35 \\
$\mathrm{~B}(\mathrm{~L} / \mathrm{mol})$ & 2.5 & $1 / \mathrm{n}$ & 0.56 \\
$\mathrm{R}_{\mathrm{L}}$ & 0.8 & $\mathrm{R}^{2}$ & 0.789 \\
$\mathrm{R}^{2}$ & 0.998 & & \\
\hline
\end{tabular}

azo dyes. The adsorption reaction isotherms of the model fitted by Least Square Method (LSM). The result shows in this study that the Langmuir model fit better than the Freundlich model. The adsorption activity of metal oxides nanoparticle samples prepared by the green source was observed against the degradation of colored azo dye by plotting graph $\mathrm{b} / \mathrm{w} \log \mathrm{q}_{\mathrm{e}}$ and $\log \mathrm{C}_{\mathrm{e}}$ as shown in Table 5 and Fig. 12.

The comparison of the adsorption model has been carried out regarding different factors - the comparison regarding the fitted model on experimental data on degradation, the residual sum of squares and intercept of slope values. After extensive experimentation, it has been observed that Freundlich kinetic model does not fit well on the experimental data as shown in Table 5.

Regression value from Langmuir kinetic model graph was calculated as 0.998 , which shows the best fitting experimental data. The Freundlich model does not fit well with data by having a standard error of 0.114 and $\mathrm{R}^{2}$ value of 0.789 .

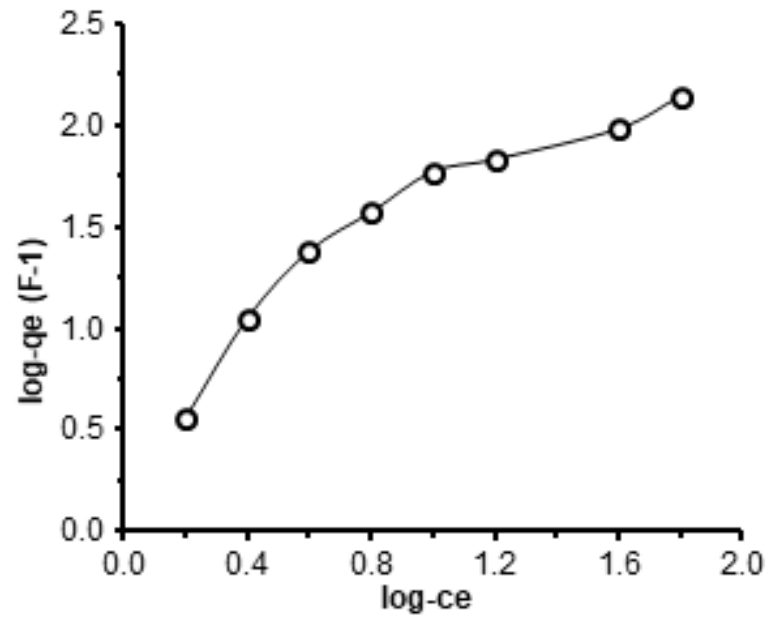

Fig 12. Freundlich isotherm model of nanoparticles

\section{- CONCLUSION}

In this paper, experimentation for the green synthesis of copper oxide nanoparticles using leaves extract of aloe vera plant has been carried out. This ecofriendly method of synthesis of nanoparticles has been recommended over physicochemical methods. The green synthesized copper oxide nanoparticles are costeffective biogenic molecules with the capability to serve as dye absorbents. It has been concluded after a more indepth analysis of nanotechnology for the synthesis of nanoparticles, that these methods are safer and cheaper. Also, it is the best way of using natural plants for the synthesis by avoiding the toxic and expensive chemicals. There is a vast variety of plants, with the potential to be used for the synthesis but the chemists and scientists have not utilized them for the synthesis. The synthesized nanoparticles can be used in different field like biochemistry, pharma, agriculture, and industry. It has proved by the experiments that copper oxide nanoparticles can remove carcinogenic dyes.

In the present study, Congo red dye was removed by nanoparticles and the effect of concentration of nanoparticles, $\mathrm{pH}$, and contact time was observed which was satisfactory. Langmuir isotherm was drawn for results which prove the linear regression curve. The maximum contact time was $10 \mathrm{~min}, \mathrm{pH} 2$, and $5 \mathrm{mg} / \mathrm{g}$ of 
nanoparticle has proved green synthesized copper nanoparticles, as the best condition for removing the Congo red dye.

\section{- REFERENCES}

[1] Kumar, P.P.N.V., Shameem, U., Kollu, P., Kalyani, R.L., and Pammi, S.V.N., 2015, Green synthesis of copper oxide nanoparticles using aloe vera leaf extract and its antibacterial activity against fish bacterial pathogens, BioNanoScience, 5 (3), 135-139.

[2] Venkatesha, T.G., Viswanatha, R., Nayaka, Y.A., and Chethana, B.K., 2012, Kinetics and thermodynamics of reactive and vat dyes adsorption on $\mathrm{MgO}$ nanoparticles, Chem. Eng. J., 198-199, 1-10.

[3] Somboonwong, J., Thanamittramanee, S., Jariyapongskul, A., and Patumraj, S., 2000, Therapeutic effects of aloe vera on cutaneous microcirculation and wound healing in second degree burn model in rats, J. Med. Assoc. Thai., 83 (4), 417-425.

[4] Khataee, A., Safarpour, M., Vahid, B., and Akbarpour, A., 2014, Degrading a mixture of three textile dyes using photo-assisted electrochemical process with $\mathrm{BDD}$ anode and $\mathrm{O}_{2}$-diffusion cathode, Environ. Sci. Pollut. Res., 21 (14), 8543-8554.

[5] Khataee, A.R., Pons, M.N., and Zahraa, O., 2009, Photocatalytic degradation of three azo dyes using immobilized $\mathrm{TiO}_{2}$ nanoparticles on glass plates activated by UV light irradiation: Influence of dye molecular structure, J. Hazard. Mater., 168 (1), 451457.

[6] Mahmoodi, N.M., 2011, Equilibrium, kinetics, and thermodynamics of dye removal using alginate in binary systems, J. Chem. Eng. Data, 56 (6), 28022811.

[7] Mahmoodi, N.M., 2013, Magnetic ferrite nanoparticle-alginate composite: Synthesis, characterization and binary system dye removal, $J$. Taiwan Inst. Chem. Eng., 44 (2), 322-330.

[8] Das, S.K., Dickinson, C., Lafir, F., Brougham, D.F., and Marsili, E., 2012, Synthesis, characterization and catalytic activity of gold nanoparticles biosynthesized with Rhizopus oryzae protein extract, Green Chem., 14 (5), 1322-1334.

[9] Nasrollahzadeh, M., Maham, M., and Sajadi, S.M., 2015, Green synthesis of $\mathrm{CuO}$ nanoparticles by aqueous extract of Gundelia tournefortii and evaluation of their catalytic activity for the synthesis of $\mathrm{N}$-monosubstituted ureas and reduction of 4nitrophenol, J. Colloid Interface Sci., 455, 245-253.

[10] Iravani, S., 2011, Green synthesis of metal nanoparticles using plants, Green Chem., 13 (10), 2638-2650.

[11] Buzea, C., Pacheco, I.I., and Robbie, K., 2007, Nanomaterials and nanoparticles: Sources and toxicity, Biointerphases, 2 (4), MR17-MR71.

[12] Nadagouda, M.N., Castle, A.B., Murdock, R.C., Hussain, S.M., and Varma, R.S., 2010, In vitro biocompatibility of nanoscale zerovalent iron particles (NZVI) synthesized using tea polyphenols, Green Chem., 12 (1), 114-122.

[13] Pérez, Y.Y., Jiménez-Ferrer, E., Zamilpa, A., Hernández-Valencia, M., Alarcón-Aguilar, F.J., Tortoriello, J., and Román-Ramos, R., 2007, Effect of a polyphenol-rich extract from aloe vera gel on experimentally induced insulin resistance in mice, Am. J. Chin. Med., 35 (6), 1037-1046.

[14] Rodríguez-Bigas, M., Cruz, N.I., and Suárez, A., 1988, Comparative evaluation of aloe vera in the management of burn wounds in guinea pigs, Plast. Reconstr. Surg., 81 (3), 386-389.

[15] Wang, Z.L., 2004, Functional oxide nanobelts: Materials, properties and potential applications in nanosystems and biotechnology, Annu. Rev. Phys. Chem., 55, 159-196.

[16] Aehle, W., 2007, Enzymes in Industry: Production and Applications, Wiley-VCH Verlag GmbH \& Co. KGaA, Weinheim, Germany.

[17] Zuas, O., Budiman, H., and Hamim, N., 2013, Synthesis of $\mathrm{ZnO}$ nanoparticles for microwave induced rapid catalytic decolorization of Congo red dye, Adv. Mater. Lett., 4 (9), 662-667.

[18] Rajasekaran, S., Sivagnanam, K., Ravi, K., and Subramanian, S., 2004, Hypoglycemic effect of aloe 
vera gel on streptozotocin-induced diabetes in experimental rats, J. Med. Food, 7 (1), 61-66.

[19] Gunalan, S., Sivaraj, R., and Venckatesh, R., 2012, Aloe barbadensis Miller mediated green synthesis of mono-disperse copper oxide nanoparticles: Optical properties, Spectrochim. Acta, Part A, 97, 1140-1144.

[20] Kumar, P.P.N.V., Pammi, S.V.N., Kollu, P., Satyanarayana, K.V.V., and Shameem, U., 2014, Green synthesis and characterization of silver nanoparticles using Boerhaavia diffusa plant extract and their anti bacterial activity, Ind. Crops Prod., 52, 562-566.

[21] Maensiri, S., Laokul, P., Klinkaewnarong, J., Phokha, S., and Seraphin, S., 2008, Indium oxide $\left(\mathrm{In}_{2} \mathrm{O}_{3}\right)$ nanoparticles using aloe vera plant extract: Synthesis and optical properties, Optoelectron. Adv. Mater. Rapid Commun., 2 (3), 161-165.

[22] Surjushe, A., Vasani, R., and Saple, D.G., 2008, Aloe vera: A short review, Indian J. Dermatol., 53 (4), 163166.

[23] Narasaiah, P., Mandal, B.K., and Sarada, N.C., 2017, Biosynthesis of copper oxide nanoparticles from Drypetes sepiaria leaf extract and their catalytic activity to dye degradation, IOP Conf. Ser. Mater. Sci. Eng., 263, 022012.

[24] Scherrer, P., 1918, Bestimmung der Größe und der inneren Struktur von Kolloidteilchen mittels Röntgenstrahlen, Nachrichten von der Gesellschaft der Wissenschaften zu Göttingen, MathematischPhysikalische Klasse, 1918, 98-100.

[25] Rajabi, H.R., Arjmand, H., Hoseini, S.J., and Nasrabadi, H., 2015, Surface modified magnetic nanoparticles as efficient and green sorbents: Synthesis, characterization, and application for the removal of anionic dye, J. Magn. Magn. Mater., 394, 7-13.

[26] Saif, S., Tahir, A., Asim, T., and Chen, Y., 2016, Plant mediated green synthesis of $\mathrm{CuO}$ nanoparticles: Comparison of toxicity of engineered and plant mediated $\mathrm{CuO}$ nanoparticles towards Daphnia magna, Nanomaterials, 6 (11), E205.

[27] Ghaedi, M., Hajjati, S., Mahmudi, Z., Tyagi, I., Agarwal, S., Maity, A., and Gupta, V.K., 2015, Modeling of competitive ultrasonic assisted removal of the dyes - Methylene blue and Safranin$\mathrm{O}$ using $\mathrm{Fe}_{3} \mathrm{O}_{4}$ nanoparticles, Chem. Eng. J., 268, 2837.

[28] Langmuir, I., 1917, The Constitution and fundamental properties of solids and liquids. II. Liquids, J. Am. Chem. Soc., 39 (9), 1848-1906.

[29] Du, W.L., Xu, Z.R., Han, X.Y., Xu, Y.L., and Miao, Z.G., 2008, Preparation, characterization and adsorption properties of chitosan nanoparticles for eosin $\mathrm{Y}$ as a model anionic dye, J. Hazard. Mater., 153 (1-2), 152-156. 